\title{
THE EFFECTIVENESS OF INTRAPERITONEAL HYDROCORTISONE ON POST-OPERATIVE PAIN IN LAPAROSCOPIC CHOLECYSTECTOMY
}

\author{
Rakesh C1, Hema Latha Dunna², Aparanji K
}

${ }_{1}^{1}$ Assistant Professor, Department of Anaesthesia, Andhra Medical College, Visakhapatnam, Andhra Pradesh, India.

${ }_{2}^{2}$ Assistant Professor, Department of Anaesthesia, Andhra Medical College, Visakhapatnam, Andhra Pradesh, India.

${ }^{3}$ Associate Professor, Department of Anaesthesia, Andhra Medical College, Visakhapatnam, Andhra Pradesh, India.

ABSTRACT

\section{BACKGROUND}

Postoperative pain can increase the morbidity and prolong hospital stay after laparoscopic cholecystectomy. Intraperitoneal analgesia is a component of multimodal approach to postoperative analgesia which is being increasingly investigated. We wanted to compare the effect of intraperitoneal hydrocortisone with intraperitoneal bupivacaine with regard to pain relief after laparoscopic cholecystectomy.

\section{METHODS}

30 patients who were given intraperitoneal Bupivacaine and 30 patients who were given intraperitoneal Hydrocortisone were included in the study. Patients were followed regarding postoperative abdominal and shoulder pain using VAS score based on a 0 10 scale at 2, 4, 8, 12 and 24 hours and analgesic requirements postoperatively.

\section{RESULTS}

Patients in the Bupivacaine group had significantly lower abdominal and shoulder VAS scores. Statistically significant difference in abdominal VAS score was noted at 4 hours and 8 hours $(\mathrm{p}=0.031)$ postoperatively. With respect to shoulder pain VAS score, a statistically significant difference was noted at 8 hours and 12 hours $(\mathrm{p}=0.031)$. Requirement of rescue analgesia was also less in Bupivacaine group.

\section{CONCLUSIONS}

Intraperitoneal administration of Hydrocortisone is not as effective as intraperitoneal Bupivacaine in decreasing pain and analgesic requirements after laparoscopic cholecystectomy.

HOW TO CITE THIS ARTICLE: Rakesh C, Dunna HL, Aparanji K. The effectiveness of intraperitoneal hydrocortisone on postoperative pain in laparoscopic cholecystectomy. J. Evolution Med. Dent. Sci. 2019;8(17):1381-1384, D0I: $10.14260 /$ jemds/2019/307

\section{BACKGROUND}

Laparoscopic cholecystectomy is the treatment of choice for symptomatic cholelithiasis. ${ }^{1}$ There are several advantages for this procedure when compared to open cholecystectomy. They include a reduction in stress response, postoperative pain, wound infection rate, intraoperative bleeding, impairment of respiratory function and pulmonary complications, a shorter recovery time and better cosmetic appearance. ${ }^{2}$ Although there are many benefits of laparoscopic surgery, postoperative pain is still a major complaint that can prolong hospital stay and lead to increased morbidity, which is particularly important in centers performing this surgery as a day case procedure. ${ }^{3}$

Post laparoscopic pain is multifactorial and one of the major factors contributing to early postoperative pain is irritation of peritoneum.

'Financial or Other Competing Interest': None.

Submission 11-03-2019, Peer Review 18-04-2019,

Acceptance 23-04-2019, Published 29-04-2019.

Corresponding Author:

Hema Latha Dunna,

C/o. Dr. K. Murali Krishna,

SF-102, Sai Nilayam, D. No. 16-61/6,

Near Ramalayam Pothenia Mallayapalem,

Visakhapatnam-530041,

Andhra Pradesh,

India.

E-mail: latha2004@yahoo.com

DOI: $10.14260 /$ jemds $/ 2019 / 307$

Multimodal approach to postoperative analgesia following laparoscopic cholecystectomy includes systemic (Opioids and nonopioids) analgesics and regional (neuraxial and peripheral) analgesic techniques. Administration of intraperitoneal local anaesthetics (IPLA) ${ }^{4}$ alone or in combination with nonopioid analgesics is considered as an easy, cheap and non-invasive method which provides good postoperative analgesia following laparoscopic surgery. ${ }^{5}$

The use of steroids for postoperative pain relief is well documented. 6 Local anaesthetics and steroids are used for intraperitoneal administration in laparoscopic surgeries. Steroids play a crucial role in the regulation of inflammatory responses through both genomic and nongenomic mechanisms and may reduce pain. ${ }^{7}$ The proposed mechanism of action include suppression of tissue levels of prostaglandin production leading to inhibition of the synthesis of the cyclooxygenase isoform- 2 in peripheral tissues and in the central nervous system and also the inhibition of other mediators of inflammatory hyperalgesia like tumour necrosis factor-alfa, interleukin-17b, and interleukin-6. Dexamethasone is a corticosteroid that has been used widely to reduce postoperative pain. The effect of intraperitoneal hydrocortisone on pain relief in laparoscopic cholecystectomy has been evaluated in recent studies.

The purpose of this study is to compare the effect of intraperitoneal Hydrocortisone with Bupivacaine in reducing the postoperative pain and other postoperative morbidities after laparoscopic cholecystectomy. 


\section{Aim and Objectives}

To compare the effect of intraperitoneal hydrocortisone with intraperitoneal bupivacaine with regard to pain relief after laparoscopic cholecystectomy.

\section{METHODS}

An experimental randomised controlled trial was conducted in 60 patients of ASA grade I \& II undergoing laparoscopic cholecystectomy in King George hospital Visakhapatnam during January 2018-19 after obtaining permission from institutional ethical committee and written and informed consent from the patient with null hypothesis that intraperitoneal Hydrocortisone is as effective as Bupivacaine for pain relief. Patients are randomly allotted into two groups based on the last digit in the in-patient form into Group BP with patient having even numbers and group $\mathrm{HC}$ with patients having odd numbers. Group BP- 30 patients are given intraperitoneal Bupivacaine. Group HC-30 patients are given intraperitoneal Hydrocortisone.

Patients between 18-60 years, ASA grade I \&II, uncomplicated symptomatic gallstone disease are included in the study. Patients who refused surgery, use of tranquilizers, steroids, NSAIDs and alcohol abuse, allergy to corticosteroids, allergy to local anaesthetics, contraindication for pneumoperitoneum, chronic pain disease other than gallstone disease, patients with bleeding disorders and patients in whom procedure had to be converted into open cholecystectomy or in whom abdominal drain was put are excluded from study.

Sample size required is calculated from Boddy et $\mathrm{al}^{4}$ average standard deviation was taken as 0.8 . To get $80 \%$ power and $95 \%$ confidence level and to detect mean difference of 0.6 as statistically significant, we will need 29.25 subjects in each group. Hence, we have taken a sample size of 30 subjects in each group.

A pre-anaesthetic check-up was done for all the patients which include a detailed history, general physical and systemic examination. Basic investigations were done, patients were trained how to use visual analogue scale. Patients were kept NPO overnight. In the operating room after securing an intravenous line $5 \mathrm{ml} / \mathrm{kg}$ of ringer lactate was given. Patients were premedicated with IV Glycopyrrolate $0.01 \mathrm{mg} / \mathrm{kg}$, IV Midazolam $0.05 \mathrm{mg} / \mathrm{kg}$, and IV Fentanyl $2 \mu \mathrm{g} / \mathrm{kg}$ and induced with IV Propofol $2 \mathrm{mg} / \mathrm{kg}$. Endotracheal intubation was done with IV Vecuronium 0.1 $\mathrm{mg} / \mathrm{kg}$. Anaesthesia was maintained with nitrous oxide $50 \%$ and oxygen $50 \%$ and IV infusion of Propofol (25-75 $\mu \mathrm{gm} / \mathrm{kg} / \mathrm{min}$ ) so as to maintain pulse rate and mean arterial pressure within $20 \%$ of baseline. All patients received 1 $\mu \mathrm{g} / \mathrm{kg}$ Fentanyl hourly and repeated bolus of Vecuronium to maintain relaxation. Each trocar site was infiltrated before incision with $3 \mathrm{ml}$ of lignocaine $2 \%$.

Before insufflations of $\mathrm{CO} 2$, group $\mathrm{HC}$ patients were given instillation of $100 \mathrm{mg}$ Hydrocortisone in $250 \mathrm{ml}$ of normal saline into the peritoneal cavity. Similarly group BP patients received $100 \mathrm{mg}$ Bupivacaine in $250 \mathrm{ml}$ normal saline into peritoneal cavity. The instillation was performed by surgical scrub nurse. After instillation patient was positioned in Trendelenburg, anti-Trendelenburg, left and right lateral decubitus and finally in supine position for spread of drug for a period of 2 minutes in each position before positioning the patient in anti-Trendelenburg position with left tilt (10 degrees) for surgery. Vitals like heart rate, non-invasive blood pressure, SP02, ETCO2 and ECG are monitored throughout surgery. Towards end of procedure propofol infusion was tapered and turned off. Muscle relaxation was reversed with IV Glycopyrrolate $0.01 \mathrm{mg} / \mathrm{kg}$ and IV Neostigmine $0.05 \mathrm{mg} / \mathrm{kg}$ after satisfactory recovery patient is extubated and shifted to post-operative recovery room.

For all measurements, the time of extubation is considered as 0 . Patients were followed regarding postoperative abdominal pain which include parietal pain, visceral pain and shoulder pain using visual analogue scale based on 0-10 scale at 2, 4, 8, 12 and 24 hours after the operation.

Injection Diclofenac $75 \mathrm{mg}$ IV was given after test dose as rescue analgesic for VAS more than 4 postoperatively.

\section{Statistical Analysis}

Data was entered into MS Excel and analysed using SPSS. Descriptive analysis was done. Mean and standard deviation was calculated for all quantitative variables. Qualitative variables were expressed as percentage. Student ' $t$ ' test was looked for difference between Bupivacaine and Hydrocortisone groups with respect to quantitative variables. To study the difference between Bupivacaine and Hydrocortisone groups with regards to use of rescue analgesic Chi-square test was used.

\section{RESULTS}

\begin{tabular}{|c|c|c|}
\hline Age (Years) & Bupivacaine & Hydrocortisone \\
\hline$<30$ & 4 & 10 \\
\hline $30-39$ & 9 & 5 \\
\hline $40-49$ & 6 & 10 \\
\hline$>50$ & 11 & 5 \\
\hline Mean \pm SD & $42.1 \pm 11.1$ & $39.2 \pm 12.2$ \\
\hline \multicolumn{2}{|c|}{ Table 1. Comparison of Age Based on Drugs } \\
\hline
\end{tabular}

The mean age of participants in the Bupivacaine group was $42.1 \pm 11.1$ and in Hydrocortisone group was $39.2 \pm 12.2$, this difference in mean age was not found to be statistically significant.

\begin{tabular}{|l|c|c|c|c|}
\hline & Bupivacaine & Hydrocortisone & t & p \\
\hline Height (cms) & $161.5 \pm 8.8$ & $159.1 \pm 7.3$ & 1.14 & 0.261 \\
\hline Weight $(\mathrm{Kgs})$ & $60.2 \pm 9.0$ & $61.7 \pm 8.5$ & 0.67 & 0.508 \\
\hline BMI $\left(\mathrm{kg} / \mathrm{m}^{2}\right)$ & $23.1 \pm 2.5$ & $24.4 \pm 2.9$ & 1.87 & 0.066 \\
\hline
\end{tabular}

Table 2. Comparison of Anthropometric Measurements

There was no statistically significant difference in height, weight and BMI in both the groups.

\begin{tabular}{|c|c|c|c|c|c|c|c|c|}
\hline \multirow{2}{*}{$\begin{array}{c}\text { Visual } \\
\text { Analogue } \\
\text { Scale } \\
\text { Abdomen }\end{array}$} & \multicolumn{3}{|c|}{ Bupivacaine } & \multicolumn{3}{|c|}{ Hydrocortisone } & \multirow[b]{2}{*}{$\mathbf{t}$} & \multirow[b]{2}{*}{$\mathbf{p}$} \\
\hline & Mean & SD & $\mathbf{N}$ & Mean & SD & $\mathbf{N}$ & & \\
\hline 2 Hours & 2.3 & 1.3 & 30 & 2.2 & 0.9 & 30 & 0.12 & 0.908 \\
\hline 4 Hours & 1.6 & 1.4 & 30 & 2.6 & 1.8 & 30 & $2.22 \AA$ & 0.031 \\
\hline 8 Hours & 1.3 & 1.3 & 30 & 2.0 & 1.2 & 30 & $2.22 \AA$ & 0.031 \\
\hline 12 Hours & 1.3 & 1.4 & 30 & 1.5 & 1.5 & 30 & 0.5 & 0.620 \\
\hline 24 Hours & 0.7 & 1.3 & 30 & 1.0 & 1.0 & 30 & 1.09 & 0.280 \\
\hline \multicolumn{9}{|c|}{$\begin{array}{l}\text { Table 3. Comparison of Visual Analogue Scale Abdomen } \\
\text { Based on Drugs }\end{array}$} \\
\hline \multicolumn{9}{|c|}{ p significant at $<0.05$ level } \\
\hline
\end{tabular}


It can be noted that there was no difference in the abdominal pain experienced as assessed on VAS at 2 hours in both the groups. Whereas significant difference in pain scores was noted between groups at 4 hours Bupivacaine 1.3 on VAS and Hydrocortisone 2.6 on $\operatorname{VAS}(\mathrm{p}=0.031)$ and at 8 hours Bupivacaine 1.3 on VAS and Hydrocortisone 2.0 on $\operatorname{VAS}(\mathrm{p}=0.031)$. Thereafter at $12 \& 24$ hours no significant difference was noted.

\begin{tabular}{|c|c|c|c|c|c|c|c|c|}
\hline \multirow{2}{*}{$\begin{array}{c}\text { Visual } \\
\text { analogue } \\
\text { Scale } \\
\text { Shoulder }\end{array}$} & \multicolumn{3}{|c|}{ Bupivacaine } & \multicolumn{3}{|c|}{ Hydrocortisone } & \multirow[b]{2}{*}{$t$} & \multirow[b]{2}{*}{ D } \\
\hline & Mean & SD & $\mathbf{N}$ & Mean & SD & $\mathbf{N}$ & & \\
\hline 2 Hours & 1.0 & 1.1 & 30 & 1.5 & 1.3 & 30 & 1.62 & 0.110 \\
\hline 4 Hours & 0.8 & 1.1 & 30 & 1.2 & 1.4 & 30 & 1.25 & 0.218 \\
\hline 8 Hours & 0.5 & 0.6 & 30 & 1.1 & 1.4 & 30 & 2.16 & 0.035 \\
\hline 12 Hours & 0.2 & 0.5 & 30 & 0.7 & 1.3 & 30 & 2.03 & 0.047 \\
\hline 24 Hours & 0.2 & 0.4 & 30 & 0.5 & 1.3 & 30 & 1.54 & 0.130 \\
\hline \multicolumn{9}{|c|}{$\begin{array}{l}\text { Table 4. Comparison of Visual Analogue Scale Shoulder } \\
\text { Based on Drugs }\end{array}$} \\
\hline \multicolumn{9}{|c|}{$\mathrm{P}$ significant at $<0.05$ level } \\
\hline
\end{tabular}

There was significant difference in shoulder pain noted between the two groups at 8 hours Bupivacaine 0.5 on VAS and Hydrocortisone 1.1 on VAS ( $\mathrm{p}=0.035)$ and at 12 hours Bupivacaine 0.2 on VAS and Hydrocortisone 0.7 on VAS $(\mathrm{p}=0.047)$. There was no significant difference in the shoulder pain experienced as assessed on VAS at 2 hours, 4 hours and 24 hours in both the groups.

\begin{tabular}{|c|c|c|c|c|c|c|}
\hline $\begin{array}{c}\text { Rescue } \\
\text { Analgesic }\end{array}$ & \multicolumn{2}{|c|}{ Bupivacaine } & \multicolumn{2}{|c|}{ Hydrocortisone } & \multirow{2}{*}{$\mathbf{X}^{2}$} & \multirow{2}{*}{$\mathbf{p}$} \\
\cline { 2 - 5 } & Count & Percent & Count & Percent & & \\
\hline Yes & 8 & 26.7 & 19 & 63.3 & \multirow{2}{*}{8.15} & \multirow{2}{*}{0.004} \\
\hline No & 22 & 73.3 & 11 & 36.7 & & \\
\hline
\end{tabular}

Table 5. Comparison of Rescue Analgesic Based on Drugs

Rescue analgesic was required in only 8 out of 30 in the Bupivacaine group where as 19 out of 30 in Hydrocortisone group. The difference was found to be statistically significant $(\mathrm{P}=0.004)$.

\section{DISCUSSION}

This is a prospective cohort study with a comparison group. 30 subjects who were given intraperitoneal instillation of Bupivacaine and 30 subjects who were given intraperitoneal Hydrocortisone were 8 included in the study.

When demographic data like age, sex, weight and height is compared in both the groups there is no significant difference in both the groups. ${ }^{9}$

\section{Pain Score}

Patients were followed regarding post-operative abdominal pain(which included both abdominal and visceral pain) and shoulder pain using Visual analogue scale(VAS) at 2, 4, 8, 12 and 24 hours after operation. Rescue analgesic was given when VAS was greater than 4 . In our study significant difference in pain score were noted between groups at 4 hours (Group BP-1.6 on VAS and Group HC-2.6 on VAS) and 8 hours (Group BP-1.3 on VAS and Group HC-2.0 on VAS).AT 2, 12 and 24 hours no significant difference was noted. A significant difference in shoulder pain was noted between the two groups at 8 hours (Group BP-0.5 on VAS and Group HC-
1.1 on VAS) and 12 hours (Group BP-0.2 on VAS and Group HC- 0.7 on VAS). At 2, 4 and 24 hours there was no significant difference noted between the groups.

Rescue analgesic was required in 8 out of 30 in the group $\mathrm{BP}$ and 19 out of 30 in group HC. This difference was found to be statistically significant $\left(x^{2}=8.15, P=0.004\right)$.

Papadima etal ${ }^{1}$ showed that IPA group with Levobupivacaine yielded less mean VAS score at rest and at movement compared to control group at all-time points $(\mathrm{P}$, 0.02 ) and the rescue analgesic consumption was greater in control group.

According to Sulekha ${ }^{5}$ mean VAS was comparatively higher in control group when compared to Bupivacaine group. It was concluded that intraperitoneal instillation of Bupivacaine was easy, cheap and non-invasive method which provide good analgesia in immediate post-operative period after laparoscopic cholecystectomy.

Saeveatani etal ${ }^{10}$ compared intraperitoneal Hydrocortisone with normal saline and found that patients in Hydrocortisone group had significantly lower abdominal pain compared (10.95 vs 12.95, P, 0.01) and Hydrocortisone group required less rescue analgesic compared tonormal saline group (151.66 $\pm 49.9 \mathrm{mg}$ vs $61.66 \pm 38.69 \mathrm{mg})$.

Amni etal11 compared the impact of intraperitoneal Hydrocortisone with Bupivacaine in laparoscopic cholecystectomy and found that patients in Hydrocortisone group had no statistical significance in abdominal and shoulder pain scores compared to Bupivacaine group.

Abdalla $^{8}$ studied the analgesic effect of adding HC to Ropivacaine intraperitoneally in laparoscopic Gynaecological surgeries and showed that by adding $100 \mathrm{mg}$ HC TO Ropivacaine can reduce postoperative pain and analgesic requirements.

Roberts et al ${ }^{12}$ concluded that intraperitoneal technique of local anaesthetic (BP) decreases postoperative pain and time of theatre recovery $(\mathrm{P}=0.04)$.

Cunniffe et $\mathrm{al}^{13}$ found that intraperitoneal irrigation of Bupivacaine in both hemidiaphragms at the end of laparoscopic surgeries significantly reduces both frequency $(\mathrm{P}=0.003)$ and intensity of shoulder pain VAS scores $(\mathrm{P}, 0,01)$ and post-operative analgesia requirement.

\section{CONCLUSIONS}

Intraperitoneal administration of Hydrocortisone reduces postoperative pain, but it was not as effective as intraperitoneal Bupivacaine in decreasing pain and in reducing analgesic requirement after laparoscopic surgeries.

\section{REFERENCES}

[1] Papadima A, Lagoudianakis EE, Antonakis P, et al. Repeated intraperitoneal instillation of levobupivacaine for the management of pain after laparoscopic cholecystectomy. Surgery 2009;146(3):475-82.

[2] Gerges FJ, Kanazi GE, Jabbour-Khoury SI. Anesthesia for laparoscopy review. J Clin Anesth 2006;18(1):6778.

[3] Boddy AP, Mehta S, Rhodes M. The effect of intraperitoneal local anesthesia in laparoscopic cholecystectomy: a systemic review and metaanalysis. Anesth Analg 2006;103(3):682-8. 
[4] Khan MR, Raza R, Zafar SN, et al. Intraperitoneal Lignocaine versus Bupivacaine after laparoscopic cholecystectomy: results of a randomized controlled trail. J Surg Res 2012;178(2):662-9.

[5] Sulekha. The effect of intraperitoneal bupivacaine for postoperative pain management in patients undergoing laparoscopic cholycyctectomy. A prospective double-blinded randomized control study. IOSR Journal of Dental and Medical sciences 2013;4(5):64-9.

[6] Buland K, Zahoor MU, Asghar A, et al. Efficacy of single dose perioperative intravenous steroids (Dexamethasone) for postoperative pain relief in tonsillectomy patients. J Coll Physicians Surg Pak 2012;22(6):349-52.

[7] Lim G, Wang S, Zeng Q et al. Spinal glucocorticoids receptors contribute to the development of morphine tolerance in rats. Anesthesiology 2005;102(4):832-7.

[8] Abdalla AM. Effect of intraperitoneal hydrocortisone ropivacaine for postoperative analgesia in laparoscopic gynecological surgery. AAMJ 2014;12(3):387-400.
[9] Shukla U, Prabhakar T, Malhotra K, et al. Intraperitoneal bupivacaine alone or with dexmeditomidine or tramadol for postoperative analgesia following laparoscopic cholycystectomy: a comparative evaluation. Indian J Anesth 2015;59(4):234-9.

[10] Sarvestani AS, Amini S, Kalhor M, et al. Intraoperitoneal hydrocortisone for pain relief after laparoscopic cholycystectomy. Saudi J Anaesth 2013;7(1):14-7.

[11] Amini S, Sarvestani AS. Comparing the impact of intraperitoneal hydrocortisone with bupivacaine on postoperative pain after laparoscopic cholecystectomy. Anesth Pain Med 2014;4(4):1-5

[12] Roberts KJ, Gilmore J, Pande R, et al. Efficacy of intraperitoneal local anesthetic techniques during laparoscopic cholecystectomy. Surg Endosc 2011;25(11):3698-705.

[13] Cunniffe GM, McAnena OJ, Dar AM, et al. A prospective randomized trial of intraoperative bupivacaine irrigation for management of shoulder tip pain following laparoscopy. Am J Surg 1998;176(3):258-61. 